\title{
The Virtual Access to Historical Documents in Public Institutions in Brazil
}

\author{
Cristiane Castellani Chagas dos Santos*, Rovilson Mafalda \\ Federal University of ABC - (UFABC) Avenida dos Estados, n. 5001 - CEP 09210-580 Santo André, SP, Brazil \\ *Corresponding Author: Cristiane Castellani Chagas dos Santos, Federal University of $A B C$ - \\ (UFABC) Avenida dos Estados, n. 5001 - CEP 09210-580 Santo André, SP, Brazil
}

\begin{abstract}
The digital transformation in institutions that guard historical documentation allows remote access to information in different ways that before the Digital Era was restricted to presently visiting. The information preservation and the possibility of disseminating historical documents contents without geographical boundaries limitations are the main reason to operate the digitization in collections and different stages of this process can be seen around the world as well as the application of different technologies. This paper reports the current possibilities of virtual access available to users of historical documents consulting services provided by institutions registered in Brazilian National Archives Council and that are located in São Paulo. A structured non-participant observation was performed with a significant group of these institutions, based on the following requirements: a) institutions presence in the global computer network; $b$ ) digitization of collections and c) existence of tools to access the digitized collection. Through the obtained data analysis are generated graphics that shown the digitization degrees in collections and of the virtual access possibilities. It is conclude that more than $50 \%$ of the institutions are realizing the digital transformation in their processes and digitizing custodied documents.
\end{abstract}

Key Words: digital transformation, historical documents, information access, digital culture, virtual users.

Abbreviations: National Archives Council (Conarq), National Institute of Geography and Statistics (IBGE)

\section{INTRODUCTION}

The main purpose of archiving records of human activity is transmitting the information contained in the guarded objects. According to Bellotto [1], documentation custodial institutions are responsible for allowing the retrieving of information contained in the objects preserved in their collections. In addition to being testimonies of historical or legal facts, the guarded documents have a scientific dissemination, cultural and social function and - with the evolution of communication technologies and social interaction observed by Matellart [2], Santaella [3] e Levy [4], among others - the computer and later the Internet started to play a fundamental role in the process of retrieving all kinds of documental records.

We build a definition for the term "document" based on Le Goff [5] and Santos [6]. They explains it as a produced object (wood boards, papyri, photographs, etc.) or collected object (geological material, for example), interpreted by a humans as a record, prove or attestation of an occurred fact. Currently, these records are guarded, preserved and consulted by the users in digital format, via virtual environment, provided by electronic media.

Brazil regulates the digital preserving and the online availability of historical and administrative documents by governmental laws. For the historical documents registered in not digital media, it is necessary that the custodial institution has a concern to digitize, so that it can make it available in electronic media. Recommendations by the National Culture Planning discourses that universal and full access to the new opportunities created by technology must be granted and a policy of digitization of collections is indispensable to allow the cultural memory records circulation [7]. The planning also says that digital convergence is the contemporary environment of circulation of culture and incentives experimental projects and digitization of public collections. 
In the next sections it is presented a qualitative analysis of the digital availability of documents collections in three types of documentation custody institutions identified in the studies by Tessitore [8], namely: Museums, Archives and Documentation Centers. The researched institutions were those that have an active registration with the National Archives Council (Conarq) and are located in the state of São Paulo, the most developed and economically important state of Brazil.

\section{Digital TranSFORMATION In DOCUMENTATION CUSTODIAL InSTITUTIONS}

Digital transformation is a term that can be understood as "the changes that digital technology causes or influences in all aspects of human life" [9]. Concerning the documentation custodial institutions Alves et al. [10] explain that the memory in times of visible advances in information technologies engenders a new look, where the new technologies contribute to the memory becoming available in a support that allows a more agile access.

Historical documentation usually is set in non-digital media, as the computers and its gadgets were accessible to the great public only after the end of 20th century, but by all their existence, custodial institutions were already using the available information technologies for purposes of preservation and administration of their collections. According to Dobedei [11], the first moment of museums informatization, for example, can be considered that one when databases were developed to register/inventory the acquired collections, being the digitization the most used technology nowadays.

Here it becomes necessary to differentiate the terms digitization (which is the transition from analog information to digital form - the binary code - and the storage in electronic media, for custody and information preserving) and digitalization, which includes changes made through technology in the institutional modus operandi. Institutional digital transformation in custodial entities is therefore the effect of combining digitization of collections and digitalization of processes and access.

Another issue, as illustrated by Bachi et al. [12] is: it is not enough to only guarantee collections preservation by digitization, "a file that can't be recovered by the user, simply does not exist for him". In the museums scope, the art historian Merete Sanderh off [13], curator and senior advisor of digital museum practice at Staten Museum for Kunst - Denmark) explains that near half of world population has internet access, and if an institution that guards different culture's records is not on line, it doesn't exist to the majority of their public, since its public is geographically dispersed.

Digitizing and make collections available online, and not to disseminate its availability, configures a lack of the processes digitalization. Sayão [14] point that, digital content does not survive without interaction, and it is necessary that the custodial institution has proactivity in its dissemination, where social interaction networks play a predominant role.

\section{Materials And Methods}

Are the custodial institutions adapting their collections to provide remote access by virtual ways? To find a answer to this question we perfom a structured observation, based on a data collecting guide. The variables of data collecting guide were developed to clarify:

(1) If each analyzed institution is present in digital media, through an institutional page;

(2) If it presents a searching tool for the digitized content and

(3) If it publicizes its activities in social networks, issues that configure a minimal adaptation to digital transformation.

We systematically verified the variables during the observation of each unit of the sample. The following table 1 shows the variables of the data collecting guide used in this investigation.

Table1. Data collection guide.

\begin{tabular}{|c|c|c|}
\hline Internet occurrence & Collection's virtual availability & Social Networks \\
\hline None & None & None \\
\hline Page at host & Totally digitized collections & Facebook \\
\hline Governmental & Partially digitized collections & Youtube \\
\hline
\end{tabular}


The Virtual Access to Historical Documents in Public Institutions in Brazil

\begin{tabular}{|c|c|c|}
\hline Host website & Virtual exhibitions & Twitter \\
\hline Social network & Downloadable collection's guide & Instagram \\
\hline Other & & Other \\
\hline \multicolumn{2}{|c|}{ Source: Elaborated by authors } \\
\hline
\end{tabular}

The scope we defined after Conarq's website analysis was the southeastern region, where São Paulo is located. We found a total of 434 Conarq registered entities in the whole country, and 197 entities in the southeastern region.

Then the population of the sample was defined based on the definitions of documentation center, museum and archive provided by Tessitore [8], and the recognition of documental custody function (active registration) within Conarq. We found 62 documentation custodial institutions in São Paulo.

Were observed 51 pages ( $82 \%$ of total sample) due four pages were offline and another seven pages did not present any information about how to consult the collections in their custody, sorting out the entities by their characteristics, as shown in table 2 .

Table2. Custodial institutional modalities in São Paulo.

\begin{tabular}{|c|c|}
\hline Institution Modality & Occurrence \\
\hline Museums & 11 \\
\hline Archives & 22 \\
\hline Documentation Centers & 27 \\
\hline Not Found & 1 \\
\hline Hybrid & 1 \\
\hline \multicolumn{2}{|c|}{ Source: Elaborated by authors } \\
\hline
\end{tabular}

\section{Discussing The Results}

Figure 1 shows the occurrence of institutions on Internet according to the modalities of presence verified using the data collecting guide.

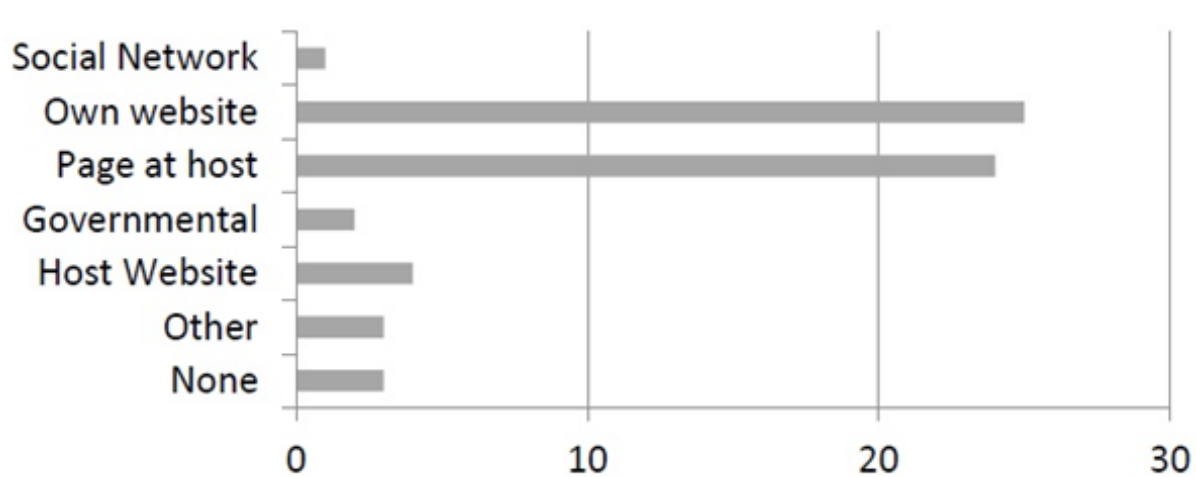

Fig1. Occurrence of the seven modalities of Internet presence. Source: Elaborated by authors.

The seven modalities of presence in Internet found were, namely:

1. None (the entity is not present in Internet);

2. Entity own website (a website related to the custodial institution itself);

3. Page at host (a page inside the website of the institution to which the custodial entity is linked);

4. Governmental (required to public administration institutions, that guard permanent value documentation); 
5. Host website (an institutional website related to the entity that hosts the custodial institution, but that don't mention the custodial institution itself);

6. Social network (as the only Internet presence at all) and

7. Other (an isolated case where we couldn't find any information about the entity at all).

We graphically represented the results of the analysis of the variables of the data collecting guide's question: collection's virtual availability in figure 2 , concluding that the information about the entity existence and its activities are generally housed in their own websites or specific pages within the sites of the institutions that host them.

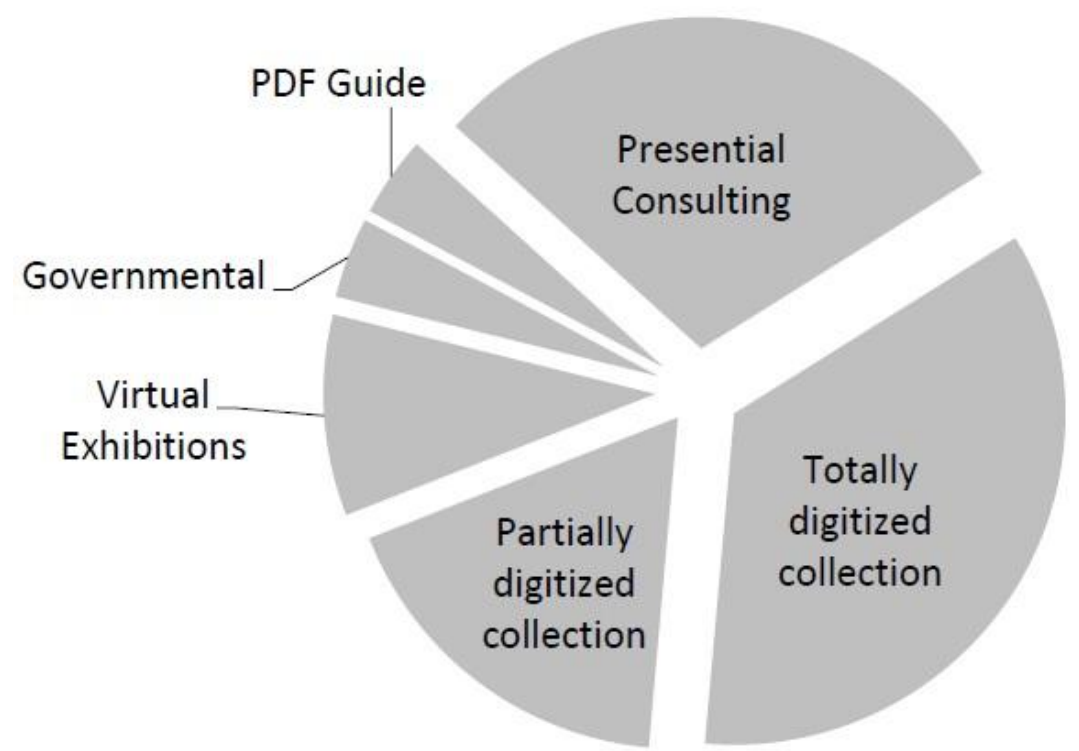

Fig2. Collection's virtual availability. Source: Elaborated by authors.

Approximately $35 \%$ of the entities analyzed provide total access to digitized collections, by some kind of searching engine. The institutions that are exclusively for visiting and presential consulting were $29.5 \%$ of the sample and in parallel these entities present in their websites information about institutional activities, such as exhibitions, events and administrative organization. Partial access to the digital archives was found between $17.5 \%$ of the pages analyzed. Virtual exhibitions in a virtual environment were practiced by $10 \%$ of the institutional websites visited, and $4 \%$ of the sample presents a kind of guide to the collection in Portable Document Format (PDF).

Government regulated public transparency websites were found in $4 \%$ of the institutions. The virtual access was analyzed by the institutional modality, getting the information that the movement to provide digital access is a concern between the three kinds of institutions, being the museums, the institutions that provide more virtual exhibitions, and the archives the institutions that are more concerned in following Brazilian laws recommendations.

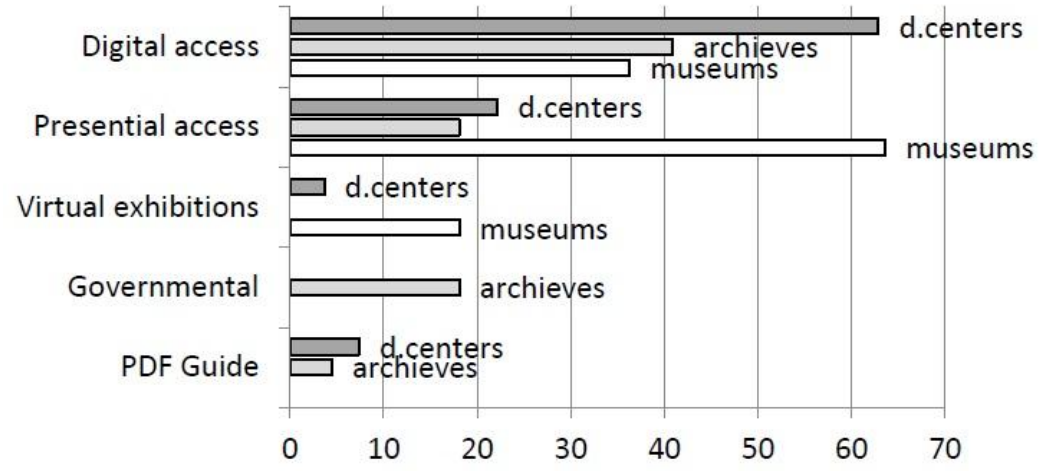

Fig3. Access modalities by entity. Source: Elaborated by authors 
Concerning the presence of the institutions in social networks, this study concluded that $21 \%$ of institutions are not in any kind of social media, while the presence of the institutions in social networks follows the worldwide tendencies showed by table 3, being the Facebook the most used social media, with the presence of $71 \%$ of the analyzed entities.

Table3. Numbers of users of the main social networks worldwide and in Brazil.

\begin{tabular}{|c|c|c|}
\hline Social Network & Worldwide active users & Brazil active users \\
\hline Facebook & 2.234 .000 .000 & 130.000 .000 \\
\hline Youtube & 1.900 .000 .000 & 98.000 .000 \\
\hline Instagram & 1.000 .000 .000 & 57.000 .000 \\
\hline \multicolumn{3}{|c|}{ Source: Elaborated by authors } \\
\hline
\end{tabular}

Youtube is the second most used social media between the institutions; $38.7 \%$ of them put videos about their activities on it. Twitter is used to communicate with users by $35.5 \%$ of institutions, and $17.7 \%$ of them are present on Instagram. The other $16 \%$ contemplates mixed social media, as Pinterest, Flickr, Vimeo and Sound cloud, not so used as the former four.

After compilation and analysis of collected data we observed that only 3 of the 62 Conarq registered entities do not have any kind of presence on the Internet. The information about the institutional existence and its activities are, in general housed in their own websites or in specific pages within the sites of the institutions that host them, and can also be found in social networks or in governmental required websites.

Approximately $29.5 \%$ of the institutional pages work exclusively by visiting for consulting, and in parallel they present information about institutional activities in their websites (such as exhibitions, events and administrative organization).

Digital access to collections was found in $52.5 \%$ of samples, $35 \%$ of them with total access to digitized collections, by searching engine, and $17.5 \%$ presenting partial access to the digital collections. The other $18 \%$ of institutions analyzed are divided between $10 \%$ that work with virtual exhibitions in a virtual environment, $4 \%$ that presents a PDF guide to collections, and $4 \%$ that presents governmental obligation websites (public transparency).

\section{CONCLUSION}

Digital transformation is occurring in all kinds of social relations in the Information age. The institutions that guard historical documents can't avoid being inserted in this new reality, which shapes the 21 st century's researchers behavior.

Our study recognizes that, in São Paulo, the transformation is ongoing since 1980's, especially in collection's preserving point of view, but it still is limited to a minimum digital adaptation (that can be seeing by the number of institutions that are concerned in put some information about its activities on line or participate in social networks). The full potential of digitized collection has not been fully explored. We can verify that almost $25 \%$ of São Paulo's analyzed entities do not have its collections online, and works exclusively with visiting, limiting geographically the research.

The concern in participation on social networks were observed in $86 \%$ of the analyzed entities, but it is also limited to the presence of an institutional page, to spread information 8 about the institution's existence, and not to disseminate the collection's contents at all. An attempt to organize virtual exhibitions was done by $10 \%$ of São Paulo's entities, which is a number that reflects the low investment in modernization of historical documentation custodial institutions.

Although the conclusion of the study indicates the current state of digital transformation of the collections, periodic monitoring of the institutions is necessary to better understand the trend curve of this process. However, this result can provide good insights for government actions in the field of culture as well as for the formulation of public policies.

\section{ACKNOWLEDGMENTS}

The authors would like to thank the professors of the graduate program in Engineering and Innovation management and CAPES to support partially the first author during this research. 


\section{REFERENCES}

[1] Belotto, H.L.: Arquivos permanentes: tratamento documental. T.A.Queiroz, São Paulo (1991).

[2] Mattelart, A.: História da sociedade da informação. 2nd edn. Loyola, São Paulo (2002).

[3] Santaella, L.: Culturas e artes do pós-humano. Paulus, São Paulo (2003).

[4] Levy, P.: Cibercultura. 3rd edn. Ed. 34, São Paulo (2010).

[5] Le Goff, J.: A história nova. 4th edn. Martins Fontes, São Paulo (1998).

[6] Santos, P.: Arquivos de cientistas: gênese documental e procedimentos de organização. Associação dos arquivistas de SP ARQSP, São Paulo (2003).

[7] Brasil. Ministério da Cultura. Plano Nacional de Cultura: diretrizes gerais. August, 2008. II Conferência Nacional de Cultura. Ministério da Cultura (2009). Available on: <cultu- ra.gov.br/site/wpcontent/uploads/2008/10/pnc_2_compacto.pdf> Access: 11.02.2018.

[8] Tessitore, V.: Como Implantar Centros de Documentação. Arquivo do Estado. Imprensa Oficial, São Paulo (2003).

[9] Stolterman, E., Fors, A.: Information technology and the good life. Information systems research. Springer, pp. 687-692 (2004).

[10] Alves, C., Cabral, M.C., Oliveira, L.: Diálogos entre arquivologia, ciência da Informação e história: uma conversa possível. In: CONGRESSO NACIONAL DE ARQUIVOLOGIA - CNA, 7., 2016, Fortaleza. Anais eletrônicos. Revista Analisando em Ciência da Informação - RACIn, João Pessoa, v. 4, special, pp. 35-50, (2016).

[11] Dobedei, V.: Culture and heritage in information age. In: Maringelli, I.C. (org.) 4TH SEMINAR ON MUSEUM INFORMATION SERVICES: DIGITAL INFORMATION AS CULTURAL HERITAGE. 4th. edn, pp. 277-286. Pinacoteca do Estado de SP, São Paulo (2017).

[12] Bachi, V. et al.: The digitization age: mass culture is quality culture. In: EUROMED 2014. INTERNATIONAL CONFERENCE, 5. Available on: <https://resources.riches- project.eu/digitizationage-mass-culture-is-quality-culture/> Access: 02.12.2019.

[13] Sanderhoff, M.: Open access can never be bad News. Medium.com, USA, 03.06.2017 (2017). Available on <medium.com/smk-open/open-access-can-never-be-bad-news- d33336aad382> Access 01.19.2019

[14] Sayão, L. F.: Digitization of cultural collections: reuse, curation and preservation. In: Ma- ringelli, I.C. (org.) 4TH SEMINAR ON MUSEUM INFORMATION SERVICES: DIGITAL INFORMATION AS CULTURAL HERITAGE. 4th. edn, pp. 245-258. Pinacoteca do Estado de SP, São Paulo (2017).

\section{AUTHORS' BIOGRAPHY}

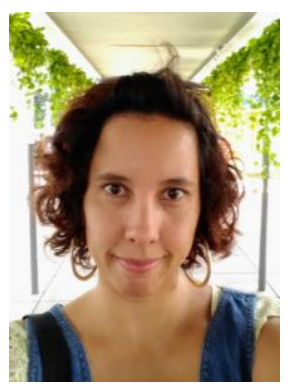

Cristiane Castellani Chagas dos Santos, Bachelor in Communication from the Methodist University of São Paulo. She obtained a Master's degree in Engineering and Innovation Management from the Federal University of ABC and the title of Specialist in Public Service Management from the same university in. Currently works as an Institutional Information Manager at the Federal University of ABC where participates in projects of university extension related to lines of research in Communication, Memory and Historical Documentation.

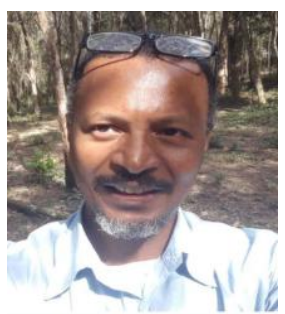

Rovilson Mafalda, Bachelor in Civil Construction Technology. He obtained Master's and PhD's degrees in Civil Engineering at the Polytechnic School of the University of São Paulo. Currently is a professor at the Federal University of ABC. Its activities include teaching and research in the undergraduate course in Instrumentation, Automation and Robotics Engineering and the postgraduate course in Engineering and Innovation Management.

Citation: Cristiane Castellani Chagas dos Santos, Rovilson Mafalda. "The Virtual Access to Historical Documents in Public Institutions in Brazil" International Journal of Humanities Social Sciences and Education (IJHSSE), vol 8, no. 7, 2021, pp. 97-102. doi: https://doi.org/10.20431/2349-0381.0807011.

Copyright: (1) 2021 Authors. This is an open-access article distributed under the terms of the Creative Commons Attribution License, which permits unrestricted use, distribution, and reproduction in any medium, provided the original author and source are credited. 